San Jose State University

SJSU ScholarWorks

Doctoral Projects

Master's Theses and Graduate Research

Spring 5-2017

\title{
The Perceptions of Registered Nurse to Bachelor of Science in Nursing Students of Motivational Interviewing
}

Christie M. Smart

California State University, Northern California Consortium Doctor of Nursing Practice

Follow this and additional works at: https://scholarworks.sjsu.edu/etd_doctoral

Part of the Other Nursing Commons

\section{Recommended Citation}

Smart, Christie M., "The Perceptions of Registered Nurse to Bachelor of Science in Nursing Students of Motivational Interviewing" (2017). Doctoral Projects. 68.

DOI: https://doi.org/10.31979/etd.qtbt-p5bf

https://scholarworks.sjsu.edu/etd_doctoral/68

This Doctoral Project is brought to you for free and open access by the Master's Theses and Graduate Research at SJSU ScholarWorks. It has been accepted for inclusion in Doctoral Projects by an authorized administrator of SJSU ScholarWorks. For more information, please contact scholarworks@sjsu.edu. 


\section{ABSTRACT \\ THE PERCEPTIONS OF REGISTERED NURSE TO BACHELOR OF SCIENCE IN NURSING STUDENTS OF MOTIVATIONAL INTERVIEWING}

Purpose: The purpose of this study was to collect information on the perceptions of motivational interviewing (MI) among Registered Nurse (RN) to Bachelor of Science in Nursing (BSN) students and whether or not the students felt it could increase holistic practice. Methodology: A qualitative descriptive study was used to collect data through semi-structured one on one interviews from six RN - BSN students post a module taught on MI. Qualitative content analysis was utilized to process the data. Findings: The students felt that MI was a useful tool for practice in improving patient communication and would contribute to holistic practice.

Christie M. Smart

May 2017 



\title{
THE PERCEPTIONS OF REGISTERED NURSE TO BACHELOR OF SCIENCE IN NURSING STUDENTS OF MOTIVATIONAL INTERVIEWING
}

by

Christie M. Smart

\author{
A project \\ submitted in partial \\ fulfillment of the requirements for the degree of \\ Doctor of Nursing Practice \\ California State University, Northern Consortium \\ Doctor of Nursing Practice
}

MAY 2017 


\section{APPROVED}

For the California State University, Northern Consortium

Doctor of Nursing Practice:

We, the undersigned, certify that the project of the following student meets the required standards of scholarship, format, and style of the university and the student's graduate degree program for the awarding of the master's degree.

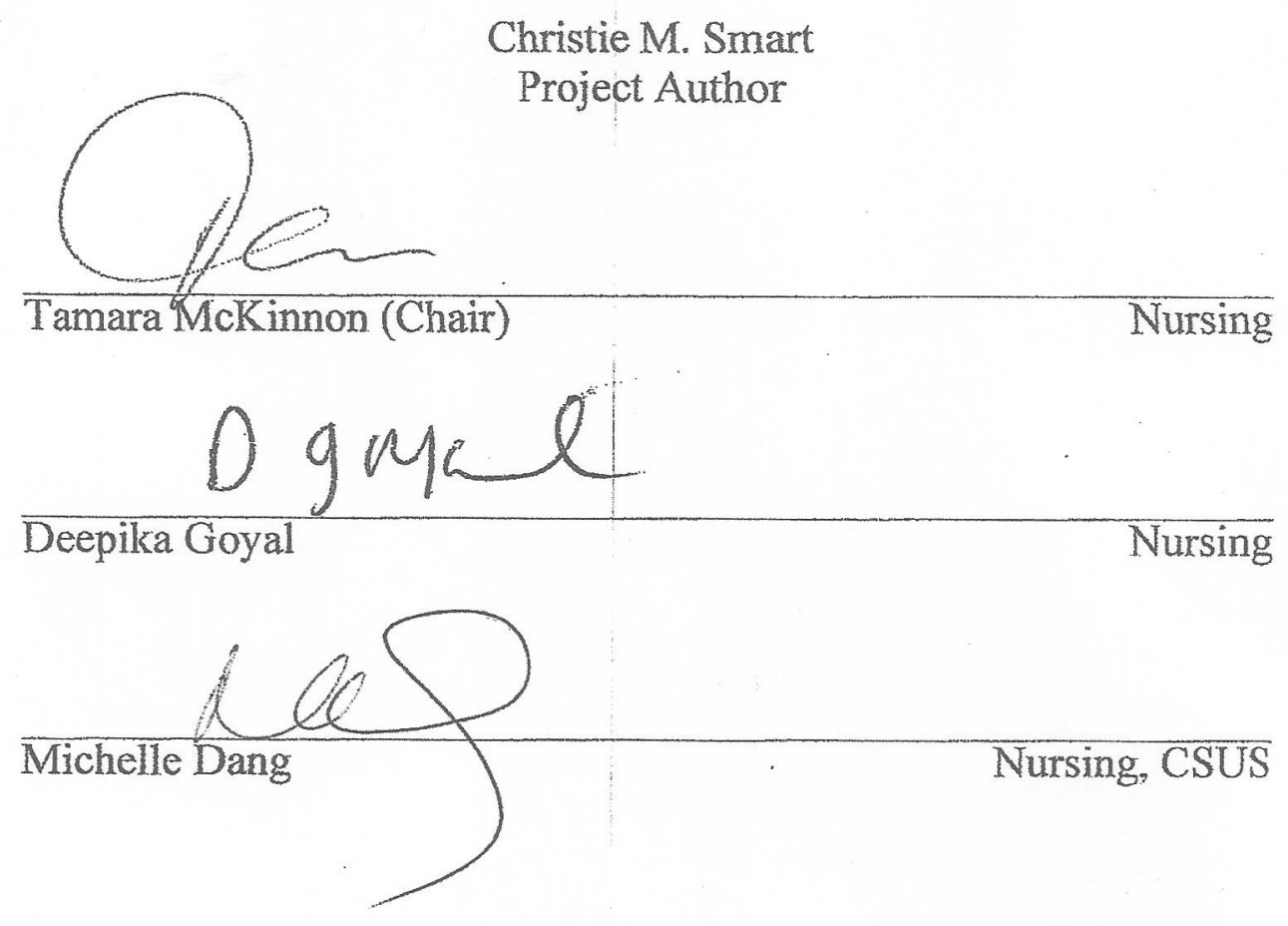




\section{AUTHORIZATION FOR REPRODUCTION}

\section{OF DOCTORAL PROJECT}

$\underline{X}$

I grant permission for the reproduction of this project in part or in its entirety without further authorization from me, on the condition that the person or agency requesting reproduction absorbs the cost and provides proper acknowledgment of authorship.

Permission to reproduce this project in part or in its entirety must be obtained from me.

Signature of project author:

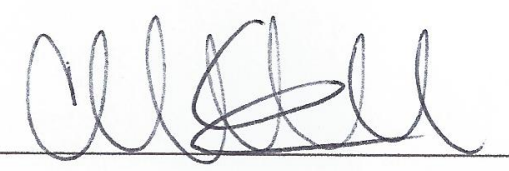




\section{ACKNOWLEDGMENTS}

I would like to thank my project chair Dr. Tamara McKinnon who was instrumental to this project in so many ways. She provided me with guidance, inspiration, support, and was always there to answer any questions I had. I would also like to thank my project committee, Dr. Deepika Goyal and Dr. Michelle Dang, both of which were always available to give feedback and direction when I was unsure of where my project was going.

A thank you goes to Dr. Lori Rodriquez as well, who has kept me on track, given me guidance and answered every little question I have asked. I have also been inspired and supported by the faculty and staff in the nursing department at California State University, Sacramento and would like to extend my thanks. My classmates in the DNP program have also provided support and inspiration that helped every step of the way.

Finally, I would like to thank my family who I could not have done this without. My husband Mike and my daughters Ashley and Lola have supported me and had patience with me and loved me through the entire project and process. 
TABLE OF CONTENTS

Page

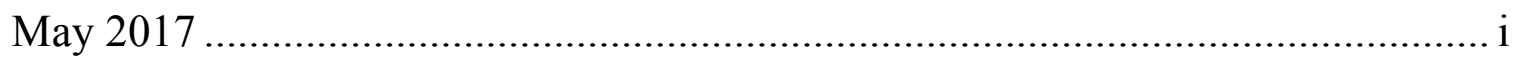

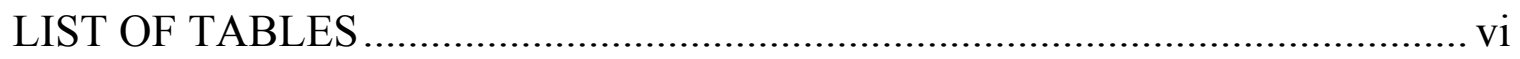

LIST OF FIGURES …........................................... Error! Bookmark not defined.

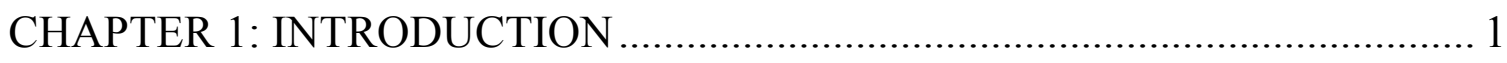

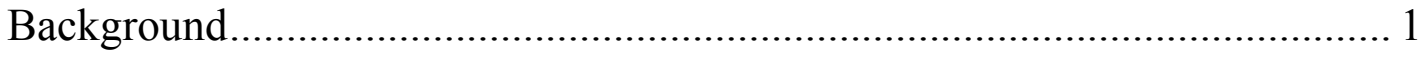

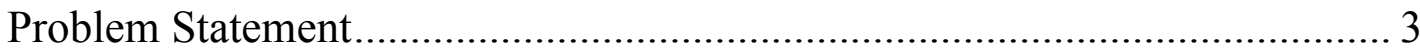

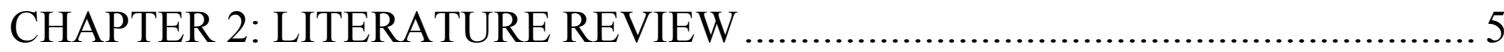

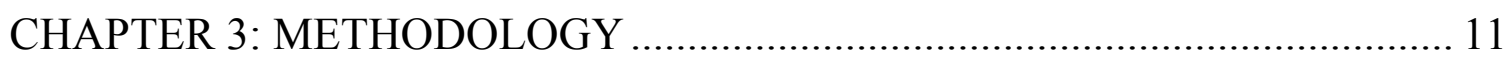

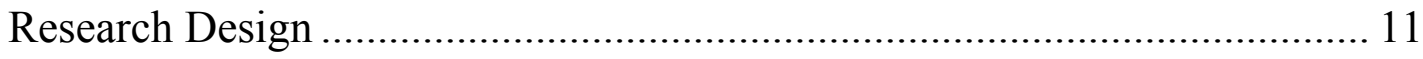

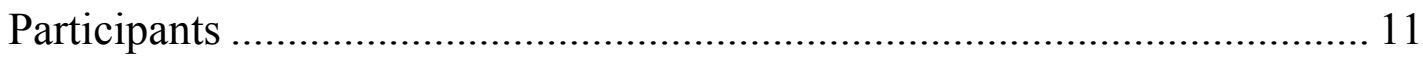

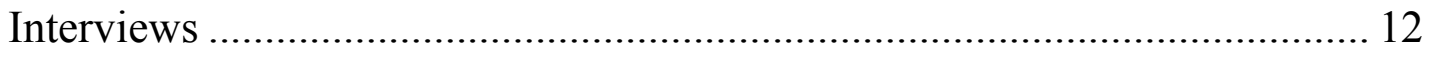

Potential Benefits and Risks ..................................................................... 12

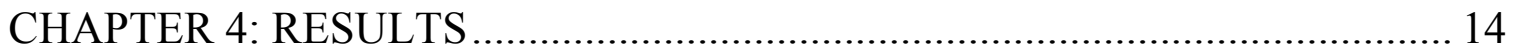

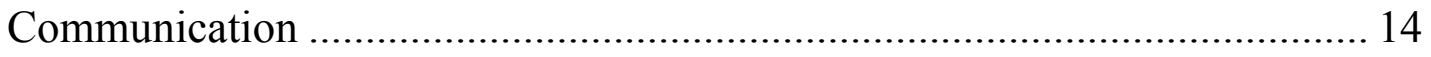

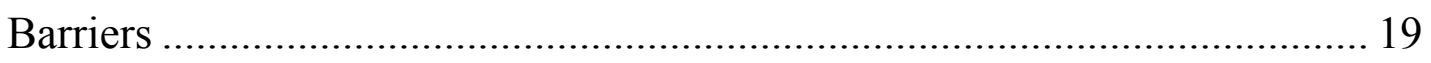

CHAPTER 5: CONCLUSION AND RECOMMENDATIONS …....................... 20 


\section{LIST OF TABLES}

Page

Table 1 Main Category, Generic and Sub-categories ...................................... 16 



\section{CHAPTER 1: INTRODUCTION}

Holistic nursing is defined by the American Holistic Nurses Association (AHNA) (2015) as an integration of nursing theory, knowledge, expertise, and intuition. This practice emphasizes the interconnectedness of multiple aspects of the patient, including social/cultural, body, mind, and spirit, all in context with the environment (AHNA). Motivational Interviewing (MI) is based upon the principles of connecting with the patient through the use of open-ended questions and reflective listening. These techniques increase the patient's ability to contribute to their care by expressing their needs and feeling included in their plan of care (Miller \& Rollnick, 2012). Patients who receive care in a holistic manner are more likely to report satisfaction with their care and have positive patient outcomes (Kinchen, 2015). The registered nurse (RN)who is returning to school to earn their Bachelor of Science in Nursing (BSN) students have returned to school to expand their knowledge by furthering their education. Little is known about the use or perception of MI among RN to BSN students. This study will explore the $\mathrm{RN}$ to BSN student's perceptions of MI and whether they feel it can increase the holism of their current nursing practice.

\section{Background}

The Bachelor of Science in Nursing program curriculum includes competencies such as community and public health, leadership, health policy, and upper division humanities courses, whereas Associate Degree in Nursing (ADN) programs focus more on the technical skills needed to become a nurse (Institute of Medicine, 2011). The RN students who have completed ADN programs are often more task oriented in their nursing practice (Connor \& Thielemann, 2013). 
Patient care environments are becoming increasingly more complex as is the patient population that is being cared for in these settings. This increase in complexity calls for nurses who are better able to provide a higher level of care (McNiesh, Rodriguez, Goyal, \& Apen, 2013). Patient care provided by nurses prepared at the BSN level has been linked to better patient outcomes. Friese, Lake, Aiken, Silber, and Sochalski (2008) found that hospitals that employ a larger percentage of baccalaureate-prepared nurses had a decrease in failure-to-rescue rates and morbidity, and mortality. Medication and procedure errors have also been found to be lower when a greater number of BSN-prepared nurses are employed (Altmann, 2012). Aiken et al. (2011) found that increasing the number of BSN nurses in a hospital by 10 percent decreased the odds of patients dying by four percent.

In order to better care for a patient population that is increasing in complexity, RNs need to be able to effectively communicate with their patients. The underlying spirit of MI is based on four central components: acceptance by the RN of the client's inherent worth, compassion and caring shown by the RN about the welfare of others, evocation of the client's strengths and internal motivation with guidance from the RN, and finally a partnership and working relationship with your client as opposed to falling into the expert role and telling them what they need to do (Miller \& Rollnick, 2013). While the foundations of MI research have been in addiction counseling, it has been shown to have positive effects in multiple lifestyle changes. These behavior changes include poor eating habits and physical inactivity (Brobeck, Bergh, Odencrants, \& Hildingh, 2011).

To provide more holistic care, the students need to understand the importance of the nurse-patient relationship. Peplau's theory of interpersonal relations (Peplau, 2004) can provide the framework from which they can use the 
techniques of MI to establish a trusting, non-judgmental relationship with their clients. Peplau (2004) identified four phases in the nurse-patient relationship. The first phase is orientation in which the patient should be approached in an open, caring manner (Peplau). The second phase is identification where the nurse and the patient begin to get to know and trust one another (Peplau). Exploitation is the third phase during which the patient takes advantage of all the services offered (Peplau). Finally, the phase of resolution is reached where the medical issue is resolved and the nurse is no longer needed (Peplau).

The heart of holistic care is the relationship that is formed between the nurse and the patient. Peplau's phases of the nurse-patient relationship can be used to guide the teaching of MI to students in the classroom and the clinical setting. Nurses must also be aware of their pre-conceived ideas in order to improve their practice, and the theory of interpersonal relations allows for the growth of not only the patient but the nurse as well (Deane \& Fain, 2015). By understanding and practicing MI through the phases of the nurse-patient relationship, the students will be able to be reflective of their current skill set and make changes to provide more holistic care.

\section{Problem Statement}

Currently, no studies exist that have examined the relationship between the use of MI and RNs providing holistic care to their patients. More specifically, there is no literature evaluating the teaching of MI to RN to BSN students. The use of MI has been linked to increased patient satisfaction, improved communication and positive outcomes in behavior change (Nesbitt, Murray, \& Mensink, 2014), making research regarding integration of $\mathrm{MI}$ in $\mathrm{RN}$ to BSN programs imperative. Nurse practitioner (NP) students showed improvement in communication and 
reported satisfaction with the introduction of MI content (Nesbitt et al., 2014). It is not known if the teaching of MI to the RN to BSN students will increase their ability to provide high-quality care that is more holistic in nature. Therefore, more information is needed on the perception of MI among the RN to BSN students and its potential for application and increasing the holistic nature of their nursing practice.

\section{Purpose of the Project}

The Institute of Medicine (2010) noted that the needs of patients and care environments are increasing in complexity. To meet these increased demands, the Institute of Medicine recommended that nurses strive for higher levels of education and emphasized the importance of finding new ways to provide this education to prepare nurses for the challenges ahead. The purpose of this study is to collect data on the RN to BSN student's perception of MI and its application to providing holistic practice. The research questions of this study are:

1) What are the perceptions of motivational interviewing among registered nurse to Bachelor of Science in Nursing students?

2) What is the registered nurse to Bachelor of Science in Nursing student's perception of motivational interviewing's potential to increase holistic practice? 


\section{CHAPTER 2: LITERATURE REVIEW}

Jansink et al. (2013) conducted a cluster randomized controlled trial to compare the MI skills of trained versus non-trained nurses one year after an educational program. The study took place in rural and urban general practices in the Netherlands. The initial number of nurses included was 65 with a total of 35 nurses completing the study. Nurses were randomly assigned to the intervention group. Nurses who were assigned to the intervention group received a total of 16 hours of training in MI techniques and educational tools that were spread out over the first six months. Blinding of the intervention group was not possible because of attendance at the training sessions. In the initial intervention group of 20 nurses, $10.0 \%$ were male, the mean age was 41.6 years, mean years of experience 4.4 , and the percentage that had MI training outside of the intervention was 30.4. In the initial control group of 23 nurses, $4.3 \%$ were male, the mean age was 43.7 years, mean years of experience were 9.7, and the percentage that had MI training outside of the intervention was 40.7. The nurses submitted video recordings of five patient encounters for baseline data, and five videos after approximately one year. The Behaviour Change Counseling Index (BECCI) checklist was used to evaluate the nurses' use of MI skills in practice. A multilevel linear regression analysis was performed. Significant improvement was found in two MI skills at the one-year follow-up compared to baseline. Significant improvement in one item on the BECCI and a significant difference in consultation time were observed in the intervention group versus the control group. A strength of this study was the use of a large number of videos to rate the MI skills of the nurses. A limitation of the study was the substantial decrease in the sample population of nurses from the beginning to the end of the study (Jansink et al., 2013). 
A quantitative descriptive study was completed by Ostlund, Kristofferzon, and Wadensten (2015) to measure the performance of primary care nurses use of MI in practice. The sample included nurses who reported receiving MI training in the past and were currently using MI with their patients. A total of 12 female nurses participated between the ages of 43-62, with 15-40 years of experience in practice. The nurses submitted three audio recorded sessions with patients for analysis and completed a questionnaire rating their MI performance. The Motivational Interviewing Treatment Code (MITI) was used to evaluate the MI skills of the nurses. MITI analysis was completed by two coders at the MITI coding laboratory. None of the nurses achieved beginning level proficiency in all variables of the MITI, and two did not achieve beginning proficiency in any of the summary scores. Analysis of the self-rating questionnaire found that the nurses overestimated their use of MI with patients when compared to the MITI scores. The nurses who scored the highest on the MITI were those who reported more extensive MI training, feedback, and support from colleagues and management. A strength of this study was the use of an independent coding laboratory to score the MITI, avoiding any researcher bias. A limitation of the study was the lack of consistency in the type and amount of MI training that the nurses received (Ostlund et al., 2015).

A one group quasiexperimental design was used by Nesbitt, Murray, and Mensink (2014) to determine if NP students demonstrated changes in interview style reflecting MI strategies after a brief educational module, valued the MI learning, and maintained skilled use after training. A convenience group of 14 first year graduate nursing students were the participants. Thirteen of the students were female, they all had, at least, five years of nursing experience, and the average age was 33 . The intervention was MI content spread over four weeks and 
included lecture, discussion, video-taped practice, experiential application, and independent reading. The participants were given a narrative pretest containing patient scenarios before the intervention and then the same test as a posttest. Video recordings of patient/provider scenarios were completed during the first face to face training session and then again during the fourth week of training. A survey regarding the student's perceptions of the value and utility of the MI learning was given at the conclusion of the training. The authors rated sample videotaped scenarios and narratives until consistency in scoring was achieved, which increased the inter-rater reliability, but an actual number was not given. Pre and post-test data were compared using paired t-tests, significant differences were found as to fewer closed questions and more open questions, and less advice giving without permission in the post data. Paired t-tests were also used to compare the pre and post videos, which showed significant changes from first to second videos in increased affirmations, and use of reflections. The participants all reported that the MI learning was useful, and $83 \%$ reported that the videotaping helped to facilitate learning. A strength of this study was the use of an MI intervention that incorporated multiple learning styles and was delivered to everyone at the same time. The use of simulation for video feedback instead of actual patient encounters could be seen as a weakness because it is a planned scenario and not reflective of the variations that actual interviews can take in practice (Nesbitt et al., 2014).

Dray, Gilchrist, Singh, Cheesman, and Wade (2014) studied the feasibility and efficacy of MI training with Mental Health Nurses (MHNs) in an eating disorder clinic. The MHNs at the facility were invited to participate, and six of fourteen agreed to take part in the study. Twenty-two patients were invited to participate in the study over the eight-month period, and 22 accepted. MHNs were 
given readings, a workbook, and a DVD on MI. The training was completed on their own time, once they had completed the materials they were given a tenquestion multiple-choice quiz to evidence adequate knowledge to begin using MI with the patients (Dray et al., 2014).

The nurses submitted video recordings of their first four MI sessions and then one additional video recording at a two-month follow-up. The MHN's were also given a survey to rate their satisfaction with the MI training at the two-month follow-up. MHN's adherence, competence, and non-adherence in MI over the five points in time were analyzed using a one-way repeated measures analysis of variance. The five time points were assessed using a repeated measures design. Chi-square was used to analyze the relapse rates and treatment adherence for the twelve months prior to MI use and the twelve months following the training (Dray et al., 2014).

The MHNs in the study showed significant improvement in their MI adherence scores and MI competence between their first session and the twomonth follow-up. They also all reported being very satisfied with the MI training. The patients also reported that the use of MI by the MHNs was enjoyable and very useful. When looking at the premature discharge rate, there was a significantly higher number prior to MI use than post intervention. A strength of this study was the use of a quiz to establish competence in MI after training was completed by the MHNs. A weakness was the very small number of MHNs participating (Dray et al., 2014).

A quasi-experimental feasibility study was used by Pfister-Minogue and Salverson (2010) to evaluate the effectiveness, feasibility, and usefulness of a behavior change counseling (BCC) training program. The participants were public health nurses (PHNs) in a rural setting in the Pacific Northwest. A total of twelve 
PHNs participated in the study, their educational background and PHN experience varied. The intervention was a one-day training on BCC that included discussion, role playing, and videos. Two follow-up phone calls to provide additional feedback and support were made by the trainer to each participant at three weeks and seven weeks post training. The nurses had three different interactions audiotaped between themselves and another nurse in a role playing situation using reallife situations. The interactions took place before the training, immediately following the training, and at eight weeks after training. An audiotaped interview was also completed during week 8 to elicit the PHNs thoughts on the training and practice experiences (Pfister-Minogue \& Salverson, 2010).

The audiotaped interactions were rated using the BECCI to evaluate and code the PHNs competence. Two researchers independently coded the interactions to address interrater reliability. The BECCI scores were analyzed using descriptive statistics. Effects sizes were calculated using Cohen's d, and Cohen's k was used to compute interrater reliability. Increased BECCI scores were demonstrated by ten of twelve PHNs immediately after the training, and two PHNs had slightly decreased scores. All PHNs demonstrated increased scores at the eight-week follow-up. PHNs reported that the one-day workshop was valuable, two of the nurses did not see the follow-up phone calls as helpful, and many of the nurses felt they would have like longer training. A strength of the study was the use of the BECCI tool; a weakness was the authors report that the second coder consistently rated the BECCI lower which created a lack of interrater reliability (posttraing $1 \mathrm{k}$ $=.0702$ and posttraining $2 k=.1423$ ) (Pfister-Minogue \& Salverson, 2010).

The use of MI by various nursing populations has been studied in the United States and other countries. The current articles in the literature mainly measure the MI proficiency of the nurse post training. (Dray, Gilchrist, Singh, 
Cheesman, \& Wade, 2014, Jansink et al., 2013, Nesbitt, Murray, \& Mensink, 2014, Ostlund, Kristofferzon, \& Wadensten, 2015, Pfister-Minogue \& Salverson, 2010). The impact of MI on patients with eating disorders (Dray, Gilchrist, Singh, Cheesman, \& Wade, 2014), and diabetes (Jansink et al., 2013) have been studied and showed positive results. The majority of these articles have focused on the use of MI by primary care nurses and show positive feedback by the nurses (Jansink et al., 2013, Ostlund, Kristofferzon, \& Wadensten, 2015). In the past MI was used most often by MHNs and this was studied by Dray, Gilchrist, Singh, Cheesman, and Wade (2014) who reported satisfaction among nurses and patients. The use of MI by PHNs for behavior counseling was shown to be a useful tool by PfisterMinogue and Salverson (2010). In the literature, the only recent study of MI training in students was with NP students (Nesbitt, Murray, \& Mensink, 2014). It appears that there is a lack of literature on the training of undergraduate nursing students to use MI in practice as well as the potential use of MI to increase the holistic nature of nursing practice. These two areas of research involving MI will both be explored in this DNP project on the potential of MI training to increase the holistic practice of RN to BSN students. 


\section{CHAPTER 3: METHODOLOGY}

\section{Research Design}

This study used a qualitative descriptive research design. Semi-structured oneon-one interviews were conducted after an in-class module on MI to gather data. The interviews were recorded and transcribed by a research assistant. The researcher reviewed the transcripts and analyzed the data utilizing qualitative content analysis.

\section{Participants}

The study subjects were RN to BSN students in their first semester Community Health course. Subjects were given information about the study and asked to participate when they attended the class in which the MI module was presented. Students interested in participating were asked to place their name and contact information on a sign-up sheet. A follow-up email was also sent to remind them of the study and encourage their participation. Twenty-seven students were present in the class on the day the module was presented. Twenty-seven students in the class met the criteria for selection. The criteria for selection were; 1) RN to BSN students enrolled in the Community Health nursing course, and 2) attendance during the teaching module on motivational interviewing. Students with less than one year of nursing experience were excluded from this study. Five were excluded from participating in the study. The primary researcher felt the students would not be able to apply what they learned about MI to their current practice without at least one year of nursing experience. Ortiz (2016) reports that new graduates lack professional confidence in their roles as RNs over the course of their first year of practice.

Thirteen students gave contact information expressing interest in participating in the study. All thirteen students were contacted by the research 
assistant to schedule interviews at the student's convenience. The end result was a total of six interviews being conducted.

A potential for a conflict of interest arose because the primary investigator is one of the instructors for the Community Health course. To avoid this conflict, the primary investigator hired and trained a research assistant to conduct the interviews. The names of the participants were kept anonymous to the primary investigator. Participants were offered an incentive to participate in the form of a $\$ 10$ gift card to Jamba Juice.

\section{Interviews}

The interviews took approximately 30-45 minutes to complete. Interviews were conducted in a debrief room in the school of nursing at California State University, Sacramento. This room was away from the classroom setting to help the participants to feel at ease. The research assistant scheduled the interviews around the participants work and school schedule for their convenience.

Informed consent was obtained from the participants. Participants were assured by the primary investigator and the research assistant that their refusal to participate in the study would in no way impact their course grade.

\section{Potential Benefits and Risks}

This study addresses a gap in the literature regarding the teaching of MI to undergraduate nursing students. Current and future students will benefit by increasing their knowledge of MI, which is a proven form of communication to improve patient outcomes (Dray, Gilchrist, Singh, Cheesman, \& Wade, 2014, Jansink et al., 2013, Nesbitt, Murray, \& Mensink, 2014, Ostlund, Kristofferzon, \& Wadensten, 2015, Pfister-Minogue \& Salverson, 2010). An increase in holistic 
practice related to the teaching of MI will result in an increase in positive patient outcomes.

There were no physical, sociological, or economic risk to the participants. There was minimal psychological risk that the participant may have felt some anxiety about answering questions related to what they were taught in the MI module. None of the participants expressed any anxiety while answering questions. The research assistant explained that if at any time the participants were anxious, the interview would be stopped and the participant permitted to discontinue their involvement if desired. There was a remote possibility of a confidentiality risk. To minimize this risk, all data was stored on a passwordprotected computer and printed data was stored in a locked file cabinet. In addition, the participant's names were not attached to the interviews. 


\section{CHAPTER 4: RESULTS}

The analysis resulted in one main theme, three generic categories, and nine sub-categories (see Table 1). The categories describe the RN to BSN student's perceptions of MI and whether it can contribute to holistic nursing practice. The main theme of the study was that MI is a useful tool in practice and could contribute to holistic nursing practice. The generic and sub-categories are based upon the RN to BSN student's responses to questions about the module on MI, if they felt it could be applied to their current nursing practice, and if MI would contribute to holistic nursing practice.

\section{Communication}

The RN to BSN students felt that the use of MI was a better method of communicating with their patients than what they were currently using. The students felt they would be better able to help the patients in their current practices by using the new MI skills learned. Some of the nurses compared MI to therapeutic communication.

\section{Listening}

The RN to BSN students felt that one of the most important concepts of MI was listening to their patients without interrupting. Several students discussed the importance of summarizing what the patient was saying back to the patient to let them know they were listening. One of the students felt that it was important to let the patient tell their story. The RN to BSN students felt that this strategy strengthened their ability to establish a relationship with the patient. One student stated: 
I've learned that it is better to just let the person you are interviewing express themselves, even though you may not agree with what they are saying at that time, it's just good to listen to what they say, rather than trying to talk while they are talking. (Interview 69)

\section{Open-ended questions}

Many of the RN to BSN students noted the importance of asking openended questions to get the patient to open up about their problems. The use of open-ended questions resulting in getting more information from the patient was noted by a couple of students.

\section{Not judging the patient}

Several of the RN to BSN students stated the importance of leaving their personal bias aside while communicating with the patient. One of the students said it was important to "identify the individuality of the patient, rather than just making your assumptions based on your own...education and cultural background.” (Interview 372)

\section{Nurse/Patient Relationship}

A positive nurse-patient relationship improves the care that the nurse is able to give to the patient (Peplau, 2004). The RN to BSN students identified MI as a way to strengthen the nurse-patient relationship. One student expressed it this way:

Well, I think if you understand what's going on in someone's life, where they come from, what their attitudes are, what they view as their obstacles, you can help them move through that and plan with them for better outcomes. (Interview 78) 
Table 1

Main Category, Generic and Sub-categories

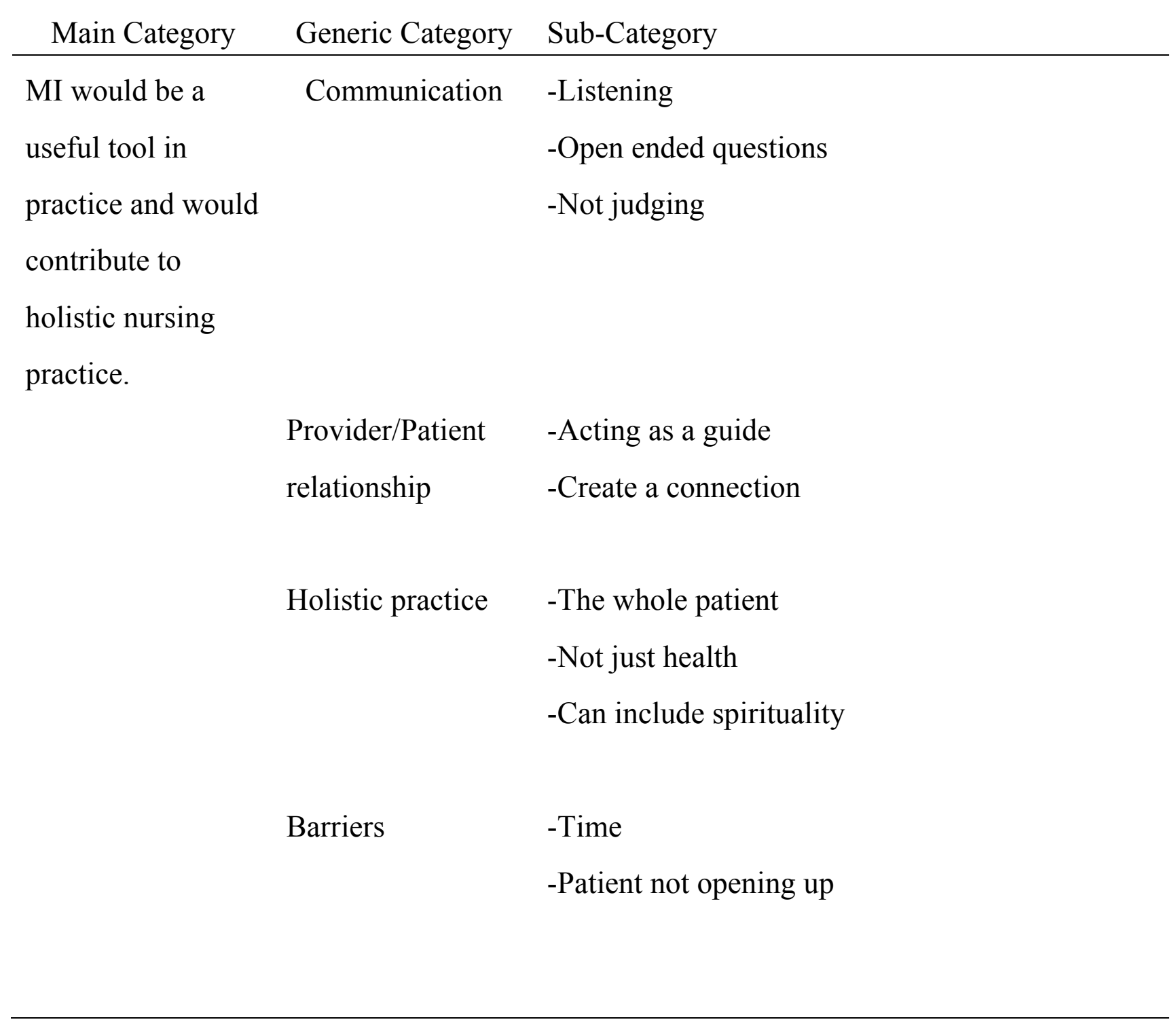

\section{Acting as a guide}

A major component of MI is for the nurse to act as a guide, not giving advice, but instead asking the client how they feel about a topic. The RN to BSN 
students saw MI as a useful tool in guiding the client to come up with solutions to their own issues. A few noted the that this would increase the likelihood that the client would take action.

I think it can be very beneficial to helping patients have a more hands on approach to their own personal care. They'll be able to identify more aspects of where they need care versus us telling them. I think it's a much better tool that just being told what to do. People put up guards against that. (Interview 96)

\section{Creating a connection}

The students described MI as a useful tool in making a connection with their patients. Using MI to work with instead of versus their patients was a frequent comment in the interviews. One student expressed it this way:

It's a much better way of communicating with patients than like quickly telling them what to do. You're going to create a much better patient relationship where they're more focused and involved in their own care. (Interview 96)

\section{Holistic Practice}

The concept of holistic nursing practice, or considering all aspects of the patient, is integral to providing a comprehensive treatment plan and positive patient outcomes. The majority of the students thought that MI would be a good tool to improving holistic care. One student noted:

I think that if you understand what's going on in someone's life, where they come from, what their attitudes are, what they view as their obstacles, you can help them move through that and plan with them for better outcomes. (Interview 78) 


\section{The Whole Patient}

MI allows the nurse to listen to the patient's story without judging and without interrupting. This allows the nurse to find out more about the patient than they might in a typical nurse/patient interaction. Several of the students described holistic practice in this way:

Holistic practice to me.... involves all the aspects of somebody's health or wellbeing.... maybe the health of the patient, the social life of the patient, like the overall wellbeing of the patient. It's not just one aspect of it. (Interview 69)

\section{Not Just Health}

The students felt that MI could be a useful tool in finding out more about the patient beyond their health issues. One student noted:

Trying to take care of the patient in other respects other than just the health issue. Holistic is addressing other parts of the patient story, so I guess that goes back to the communication, the way you're talking to them; trying to find out what other things are influencing, if it's a health issue. (Interview 78)

\section{Can Include Spirituality}

A few of the students did not see holistic practice as looking at multiple aspects of the patient, but rather looking at their spirituality in relation to their health. One student felt this allowed them to make a better connection with their patient.

Holistic, to me, feels like it's almost a spiritual thing. You get into that person's world and, you know, you're trying to help them, encourage them, just by listening and just understanding. And then, they feel better. But holistic I feel like is more a spiritual connection to your patient. (Interview 127) 


\section{Barriers}

The students were asked what they thought might hamper them from using MI in their current nursing practice. A few of the students did not believe there would be any barriers to its use, but several noted time and a lack of patient involvement in the conversation.

\section{Time}

The use of MI when interviewing a patient is more time consuming than the use of simple yes and no questions. Allowing the patient to express their thoughts and feelings can increase the amount of time needed for a nurse/patient interaction. Several of the students noted this as a barrier to the use of MI in their current practice when asked. One student noted: "Simply time. I think that's probably going to be the answer for most people is just the time element." (Interview 372).

\section{Patient Not Opening Up}

The success of MI is based upon the patient being willing to open up and discuss their story. Several of the students were concerned about this aspect of MI. One student was concerned that some patients would not be willing to participate:

A patient's ability to participate, you know. If they're not willing to give up information it might be a.... I actually think it'd be better for them if they're not coached, but sometimes they have to be coached to get any information out of them; they're just not real open people. (Interview 36) 


\section{CHAPTER 5: CONCLUSION AND RECOMMENDATIONS}

This study was able to identify that RN to BSN students could see the usefulness of MI as a communication tool with patients. The ability of the students to see MI as useful could lead to their use of MI in their current practice. While this study is not able to demonstrate that this use of MI by the RN to BSN students will lead to better patient outcomes, a link between MI and positive patient outcomes was reported by Nesbitt, Murray, and Mensink (2014). This study supports the inclusion of MI in the RN to BSN curriculum as an opportunity to increase students understanding of the potential patient benefits in using this communication tool.

To gain a deeper understanding of the impact of teaching MI to RN to BSN students further research is needed. The teaching of a more in depth MI module followed by observations in the clinical setting would further contribute to the understanding of RN to BSN students' implementation of MI into practice. This research would further support the inclusion of MI in undergraduate nursing curriculum contributing to better patient communication. 



\section{REFERENCES}

Aiken, L. H., Cimiotti, J. P., Sloane, D. M., Smith, H. L., Flynn, L., \& Neff, D. F. (2011). Effects of nurse staffing and nurse education on patient depths in hospitals with different nurse work environments. Medical Care, 49(12), 1047-1053.

Altmann, T. K. (2012). Nurses' attitudes toward continuing formal education: A Comparison by level of education and geography. Nursing Education Perspectives, 33(2), 80-84.

American Holistic Nurses Association. (2015). What is holistic nursing? Retrieved from http://ahna.org/About-Us/What-is-Holistic-Nursing

Brobeck, E., Bergh, H., Odencrants, S., \& Hildingh, C. (2011). Primary healthcare nurses' experiences with motivational interviewing in health promotion practice. Journal of Clinical Nursing, 20, 3322-3330. doi:10.1111/j.13652702.2011.03874.x

Conner, N. E., \& Thielemann, P. A. (2013). RN-BSN completion programs: Equipping nurses for the future. Nursing Outlook, 61, 458-465. doi:doi:10.1016/j.outlook.2013.03.003

Deane, W. H., \& Fain, J. A. (2015). Incorporating Peplau's theory of interpersonal relations to promote holistic communication between older adults and nursing students. Journal of Holistic Nursing, , . doi:10.1177/0898010115577975

Dray, J., Gilchrist, P., Singh, D., Cheesman, G., \& Wade, T. D. (2014). Training mental health nurses to provide motivational interviewing on an inpatient eating disorder 
unit. Journal of Psychiatric and Mental Health Nursing, 21, 652-657. doi:10.1111/jpm.12163

Friese, C. R., Lake, E., Aiken, L. H., Silber, J. H., \& Sochalski, J. (2008). Hospital nurse practice environments and outcomes for surgical oncology patients. Health Services Research, 43(4), 1145-1163. doi:10.1111/j.1475-6773.2007.00825.x Institute of Medicine. (2010). The Future of nursing: Focus on education. Washington, DC: Retrieved from The National Academies of Science website: www.iom.edu/nursing Institute of Medicine. (2011). The future of nursing: Leading changed, advancing health. Washington, DC: National Academy Press.

Jansink, R., Braspenning, J., Laurant, M., Keizer, E., Elwyn, G., Van der Weijden, T., \& Grol, R. (2013). Minimal improvement of nurses' motivational interviewing skills in routine diabetes care one year after training: A cluster randomized trial. $B M C$ Family Practice, 14(44), 44-52.

Kinchen, E. (2015). Development of a Quantitative Measure of Holistic Nursing Care. Journal of Holistic Nursing, 33(3), 238-246. doi:10.1177/0898010114563312 McNiesh, S. G., Rodriguez, L., Goyal, D., \& Apen, L. (2013). Students' lived experience in an Associate's Degree to Baccalaureate Degree Continuation Program: Opening Doors, Opening Eyes, Opening Minds. The Journal of Continuing Education in Nursing, 44(7), 326-332.

Miller, W. R., \& Rollnick, S. (2012). Motivational interviewing: Helping people change (3rd ed.). New York, New York: The Guilford Press. 
Nesbitt, B. J., Murray, D. A., \& Mensink, A. R. (2014). Teaching motivational interviewing to nurse practitioner students: A pilot study. Journal of the American Association of Nurse Practitioners, 26, 131-135. doi:10.1002/2327-6924.12041

Ortiz, J. (2016). New graduate nurses' experiences about lack of professional confidence. Nurse Education in Practice, 19, 19-24. doi:http://dx.doi.org.hmlproxy.lib.csufresno.edu/10.1016/j.nepr.2016.04.001

Ostlund, A. S., Kristofferzon, M. L., \& Wadensten, B. (2015). Primary care nurses' performance in motivational interviewing: A quantitative descriptive study. $B M C$ Family Practice, 16(89), 1-12. doi:10.1186/s12875-015-0304-z

Peplau, H. (2004). Interpersonal relations in nursing: A conceptual frame of reference for psychodynamic nursing [Kindle version]. Retrieved from Amazon.com Pfister-Minogue, K. A., \& Salverson, C. (2010). Training and experience of public health nurses in using behavior change counseling. Public Health Nursing, 27(6), 544551. doi:10.1111/j.525-1446.2010.00884. 







